\title{
Investigation of the Parameters of Low Temperature Plasma of Frequency Pulse Discharge in Relation to Air Cleaning Units
}

\author{
A. Z. Ponizovskiy, S. G. Gosteev, O. S. Kuzhel, D. E. Yurchenko \\ FMKB “Horizon" SC "SPC Gas Turbine” Salute, Moscow, Russia \\ Email: mkbgorizont@gmail.com
}

Received 7 May 2015; accepted 19 August 2015; published 26 August 2015

\begin{abstract}
In this paper, it studied parameters of low-temperature plasma (LTP) used in systems for cleaning waste gas. LTP created by positive nanosecond corona discharges, generated by high voltage pulses with a rise time of $50 \mathrm{~ns}$, duration up to $400 \mathrm{~ns}$, an amplitude up to $90 \mathrm{kV}$ and pulses repetition $50-1000 \mathrm{~Hz}$ in coaxial electrode system with gap space $3-10 \mathrm{~cm}$ through which moving air with linear velocity $v=0.01$ to $10 \mathrm{~m} / \mathrm{s}$. It was found that parameters of LTP depended on the flow velocity. The results of probe measurements of streamers current showed that on the above gaps and pulse parameters took place streamer breakdown with average field strength less than 10 $\mathrm{kV} / \mathrm{cm}$. This limits the energy input into the gas via a streamer corona and, accordingly, productivity of cleaning plants.
\end{abstract}

\section{Keywords}

Low-Temperature Plasma, Nanosecond Streamer Breakdown, Plasma Cleaning Units

\section{Introduction}

Currently being introduced systems for cleaning emissions of harmful gaseous impurities and odors based on the technology of low-temperature non equilibrium plasma (LTP) generated by nanosecond streamer discharge [1] [2]. LTP characterized by significant densities and energies of electrons capable of creating in the discharge gap high concentrations of active intermediate particles (atomic oxygen, ions and radicals), which initiate radiationchemical reactions with harmful molecules and transform them into ecologically harmless gases or aerosols.

The basis of LTP treatment systems is high-frequency pulse generators and reactor chamber (RC) with wire or multi-point (MP) corona discharge electrodes, in which the plasma-chemical reactions take place. Due to high volume density charges occurring while generating pulsed corona produces charged finely dispersed aerosols, vapors and solid particles as present in the gases, and produced as a result of conversion. The removal of charged particle from air is carried out in the pause between pulses due to the drift of molecules and particles to the grounded electrode under high DC voltage. The flushing of deposit aerosols from the wall of RC carries out by circulating water. 
The effectiveness of such systems depends on the ability of the introduction of energy into the flow of gas, so that is of particular relevance to the study of streamers multipoint electrode system, in moving air and high pulse repetition rate. Therefore, unlike many studies streamers carried out in stationary air at a single pulse, we studied the streamer in the frequency mode in the air with ozone, nitrogen oxides and other contaminated admixtures.

The results obtained allowed to optimize the design of running a series of plasma treatment installations of the “Korona M", intended for cleaning air of gaseous environmentally harmful ways and fine impurities.

\section{Experimental Procedures and Unit Contraction}

The pulses are generated by device collected by the scheme Fitch (PGF) with an odd number of steps (Figure 1) [3]. PGF consist of high-voltage charger (HV charge), a three stage of capacitors $C_{s t}$, two charging inductors $L_{d}$, switch (thyratron), transformers TR1 and TR2 and block ignition $\left(C, R_{1} R_{2}\right)$.

Charging the capacitor voltage $\left(\mathrm{U}_{\mathrm{A}}\right)$ is performed differently, resulting in a charge polarity of the secondary level is two extreme opposites, and the yield is constantly under potential equal to $U_{A}$. Generating momentum is due to the induction coup at the secondary level Cst of the bypass capacitance switch. As a result, all three voltage capacitors are formed, and the output of the impulse voltage PGF $\left(\mathrm{U}_{\mathrm{pl}}\right)$ with an amplitude equal to, $\mathrm{U}_{\mathrm{pl}} \approx 3 \mathrm{U}_{\mathrm{A}}$.

Main advantage GPVF over other capacity's pulse generators is that, in the first place, the capacitors are connected directly to the load, secondly, generation of a pulse with an amplitude equal to $3 \mathrm{U}_{\mathrm{A}}$. Switch is performed, thirdly, in the pause between pulses the load have constant potential of $U_{A}$. As a result, the unit operates as a converter of impurities and as a standard electrostatic precipitator.

Magnitude of $\mathrm{U}_{\mathrm{pl}}$ was measured with a capacitive divider $\left(\mathrm{C}_{\mathrm{HV}}, \mathrm{C}_{\mathrm{LV}}\right)$, the full discharge current $\left(\mathrm{I}_{\text {sum }}\right)$ was measured with shunt. Concentrations of gaseous impurities, oxygen and ozone gas were measured by analyzers with various types with photo ionization, photometric and electrochemical sensors. LTP was generated in the reaction chamber (RC) with the coaxial electrode system-grounded pipe and central MPD or wire electrode. Diameter (D) of RC ranged from 10 to $273 \mathrm{~cm}$, length (L) from $0.3 \mathrm{~m}$ to $4 \mathrm{~m}$, electrode spacing (d) $\mathrm{d}=3-10 \mathrm{~cm}$. Experiments were conducted at air flow rate $0.01-10 \mathrm{~m} / \mathrm{s}$.

Probe technique for measuring the parameters of the streamer [4] is to measure the current $\left(\mathrm{I}_{\mathrm{ST}}\right)$ through wire probe diameter of $0.5 \mathrm{~mm}$ the set flush with the RC wall (Figure 2) loading on resistor $\mathrm{R}_{\text {load. }}$. This allowed measurement of single streamer current after reaching the probe head streamer.

\section{Investigation of the Parameters of Streamers Probe Method.}

Using frequency PGF and multichannel oscilloscopes that operate in the pre-start on a signal that has reached a certain level, provided evidence of the development of the tape after it crossed the inter-electrode space. Figure 3

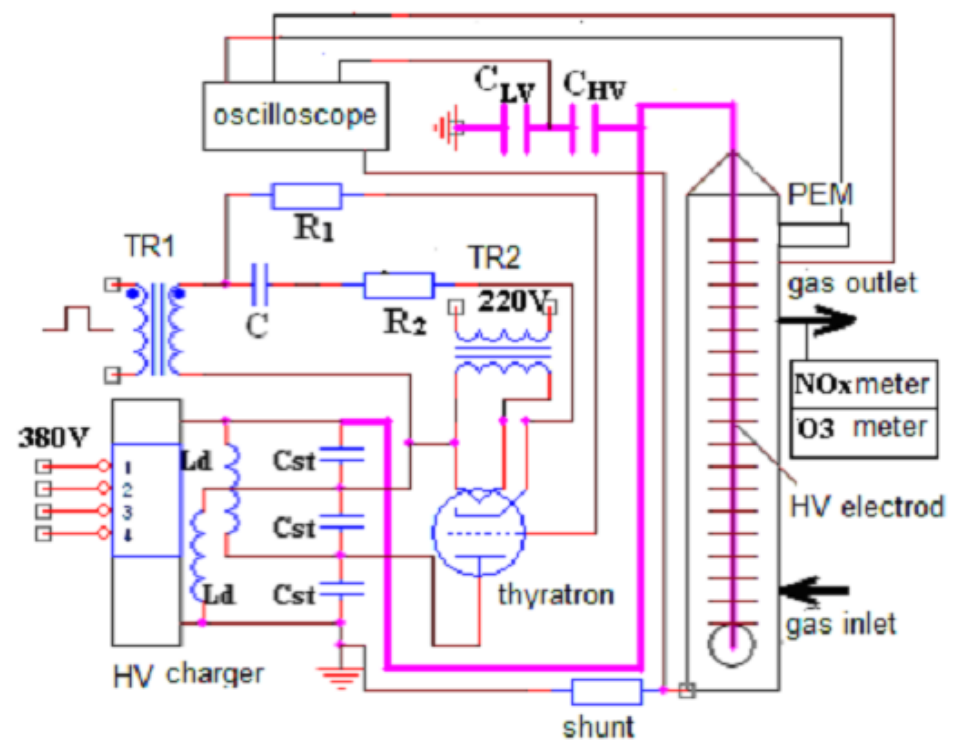

Figure 1. Schematic diagram of the experimental and industrial LTP gas cleaning unit. 


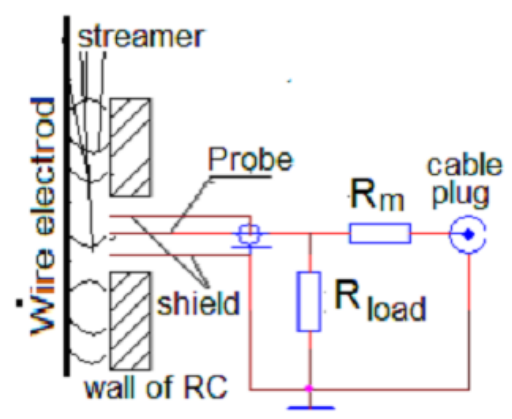

Figure 2. Schematic diagram of the probe measurements of parameters of the streamer.
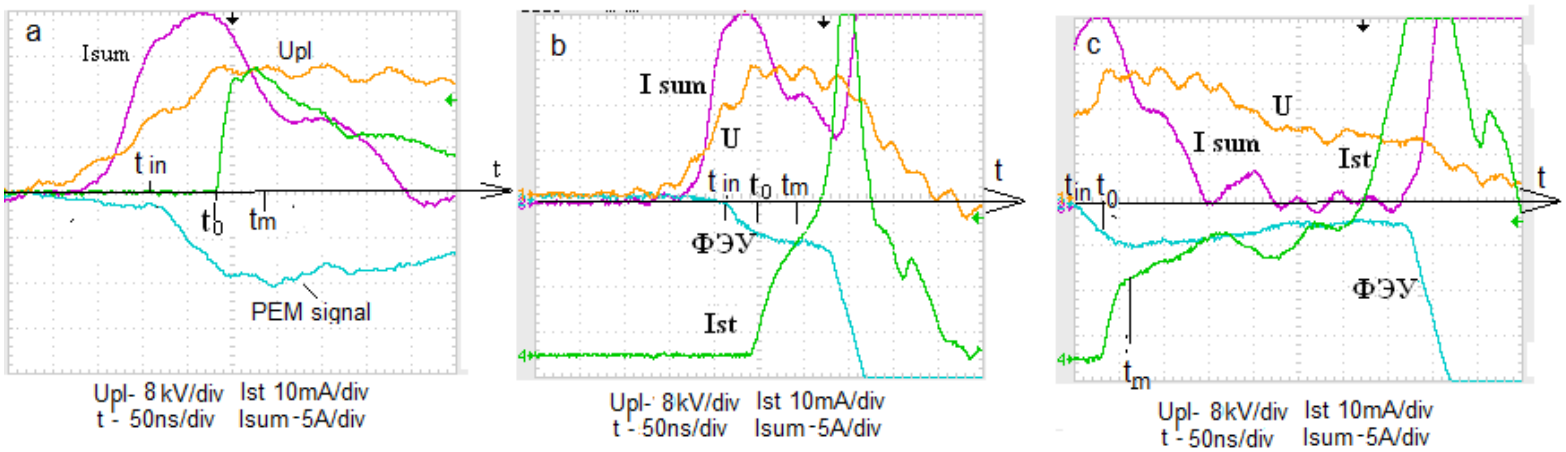

Figure 3. Three scenarios of nanosecond streamer discharges (a) no breakdown; (b) (c) breakdown.

shows waveforms of a single streamer current $\left(\mathrm{I}_{\mathrm{st}}\right)$, Isum, $\mathrm{U}_{\mathrm{pl}}$ and a signal from the photo electron amplifier(PEM) in RC with $\mathrm{D}=6 \mathrm{~cm}, \mathrm{~L}=30 \mathrm{~cm}$ and wire electrode.

We believe that the start of streamers $\left(\mathrm{t}_{\mathrm{in}}\right)$ corresponds fracture on the waveform PEM signal. In time streamers is touching the probe and is beginning register of $\mathrm{I}_{\mathrm{st}}$. Waveform of $\mathrm{I}_{\mathrm{st}}$ has a characteristic peak the duration of the $\mathrm{t}_{0}$ to $t_{\mathrm{m}}$ and then decline with some smooth portion stabilization. Such character of the current appears to be associated with the neutralization of the head of the streamer (peak) and the deionization of plasma streamer channel (part of the current recession). The time from $\mathrm{t}_{\text {in }}$ to $\mathrm{t}_{0}$ is approximately $30 \mathrm{~ns}$ that means the velocity of the streamer $\sim 10^{8} \mathrm{~cm} / \mathrm{s}$. If peak of current is the neutralization of streamer head that charge of streamer head (Q) that

$$
Q=\int_{t_{0}}^{t m} I_{s t} \cdot \mathrm{d} t
$$

Analysis static photos showed that when the wire electrode streamer corona has a discrete character, and the distance between the discharge point is about $3 \mathrm{~mm}$ and with each point starts about 10 streamers. From the dates (Figure 3$) \mathrm{Q} \approx 7.5 \times 10^{-10} \mathrm{C}$. It means that full charges $\left(\mathrm{Q}_{\text {sum }}\right)$ of one pulse is has exponent $10^{-7} \mathrm{C}$. The used Shockley relation [5], the similar value can take on the Equation (1) if $I_{\text {st }}$ replacing in $I_{\text {sum }}$ but $t_{0}-$ in $t_{\text {in }}$.

The development of the streamer after the touch probe has several scenarios. The first one (Figure 3(a)) asso-

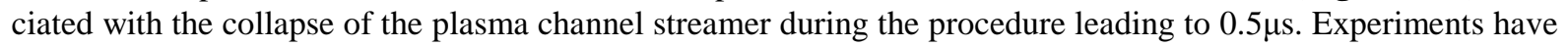
shown in the intervals $d=3-10 \mathrm{~cm}$ such a scenario takes place at the middle pulse field strength $\left(\mathrm{E}_{\mathrm{pl}}=\mathrm{U}_{\mathrm{pl}} / \mathrm{d}\right) \mathrm{E}_{\mathrm{pl}}$ $<7 \mathrm{kV} / \mathrm{cm}$.

However, with increasing $\mathrm{E}_{\mathrm{pl}}$ there are two other scenarios of the streamer development. In the first case, immediately after touching the streamer probe $\mathrm{I}_{\mathrm{st}}$ does not decrease, but increases rapidly, leading to a breakdown in the gap $\mathrm{E}_{\mathrm{pl}} \approx 8 \mathrm{kV} / \mathrm{cm}$ (Figure 3(b)). The streamer breakdown can also occur in the fall of the pulse at $\mathrm{E}_{\mathrm{pl}} \approx 5$ $\mathrm{kV} / \mathrm{cm}$ (Figure 3(c)). This current in the channel streamer after touching the probe is maintained stable for hundreds of nanoseconds at $30-50 \mathrm{~mA}$, and then increases rapidly. That's exactly streamer breakdown shows a very high rate of breakdown of $-10^{5} \mathrm{~m} / \mathrm{s}$, which is an order of magnitude greater than the maximum measured speed of leader breakdown.

Theoretically streamer breakdown was predicted in [4], but this work suggests that this effect may occur when $\mathrm{E} \approx 20 \mathrm{kV} / \mathrm{cm}$. We have shown that the streamer breakdown can occur at three times lower values of $\mathrm{E}$. 
Conducted on the basis of submissions received, calculations show that during the streamer breakdown in a power input $\approx 3 * 10^{-3} \mathrm{~J}$. It is enough for the thermal heating of the tape to a temperature of about $3000^{\circ} \mathrm{C}$, if the diameter of the conduction band of the order of the tape $0.1 \mathrm{~mm}$, which is generally coincides with both the theoretical and experimental estimates. Thus was established the cause of the breakdown of the gaps in the nanosecond pulses is a streamer, but not a leader breakdown.

\section{The Main Factors Affecting the Efficiency of Waste Treatment Equipment}

The integral electrical parameters of nanosecond corona and single streamers measurements allowed to explain the dependence of the efficiency of energy transfer into gas from $\mathrm{E}_{\mathrm{pl}}$, which directly determines the efficiency of cleaning. Figure 4 shows the frequency of occurrence of streamers on the probe $(\mathrm{N}), \mathrm{Q}, \mathrm{I}_{\text {sum }}$ and efficiency of energy transfer from a PGF into gas $(\eta)$ as a function of $\mathrm{E}$ in RC with $\mathrm{D}=23.7 \mathrm{~cm}, \mathrm{~d}=10 \mathrm{~cm}, \mathrm{l}=2 \mathrm{~m}$. The graph shows that the efficiency means of $\eta$ occurs in the range of $5<\mathrm{E}<6.5 \mathrm{kV} / \mathrm{cm}$, i.e. when streamers are all inter-electrode distance (frequency of their appearances on the probe increases by an order of magnitude) and charge their heads increases significantly. The upper limit values of $\mathrm{E}_{\mathrm{pl}}$ is the field strength at which the streamer breakdown take place.

Figure 5 shows of power input into the gas $\left(\mathrm{W}_{\mathrm{in}}\right)$, the concentration of ozone $\mathrm{kO}_{3}$, hour of ozone production $\left(\mathrm{hO}_{3}\right)$ and specific energy consumption for ozone production $\left(\mathrm{W} / \mathrm{hO}_{3}\right)$ from the air flow rate $(\theta)$. To understand the reasons for such a character of graphs in Figure 5, it was carried out simultaneous registration of integrated optical and electrical characteristics of the streamer corona discharge at different gas flow rates $\theta$ Figure 6 . Usually by nanosecond pulses at intervals of $10 \mathrm{~cm}$ in length, $\mathrm{I}_{\text {sum }}$ waveform has two or more peaks.

The first peak which appears, is capacitive and is connected to the charging current of capacitance RC, since regardless of pulse repetition rate and air flow rate, the amplitude remains unchanged (Figure 6). At the same time, the second peak which appears to be a related with streamer current essentially depends on the flow rate of air (Figure 6). If we talk about in the integrated optical detection, then a decrease in air flow rate decreases significantly luminosity process, and completely disappear bright glowing region near the tip of the anode. Apparently ozone as the electro negative gas, prevents the development of streamers. This is evidenced by the fact that the reduction of the second peak in the air with a small duct occurs gradually, in synchronization with the increase in the concentration of ozone. Because the pumping of energy in the gas is determined by the current streamer, it is easy to understand why the efficiency of ozone production increases with increasing air flow. On the other hand the value $\mathrm{GO}_{3}$ and $\mathrm{W} / \mathrm{GO}_{3}$, increases to the value $\theta$, corresponding to the transition from laminar to turbulent value, apparently because of the decrease of ozone depletion on the walls of the RC.

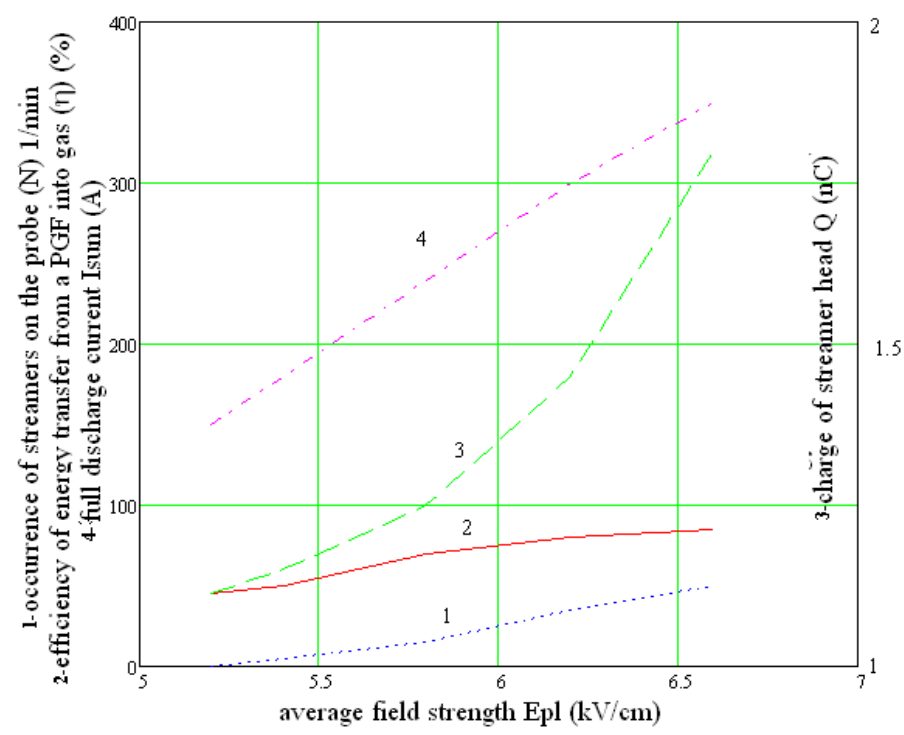

Figure 4. The dependence of the frequency of occurrence of streamers on the probe $\mathrm{N}(1)$, efficiency of energy transfer from a PGF into gas $(\eta)(2), \mathrm{Q}(3)$, $I_{\text {sum }}(4)$ as a function of $E_{p l}(R C-D=25.7 \mathrm{~cm}, d=9 \mathrm{~cm}, \mathrm{l}=2 \mathrm{~m})$. 


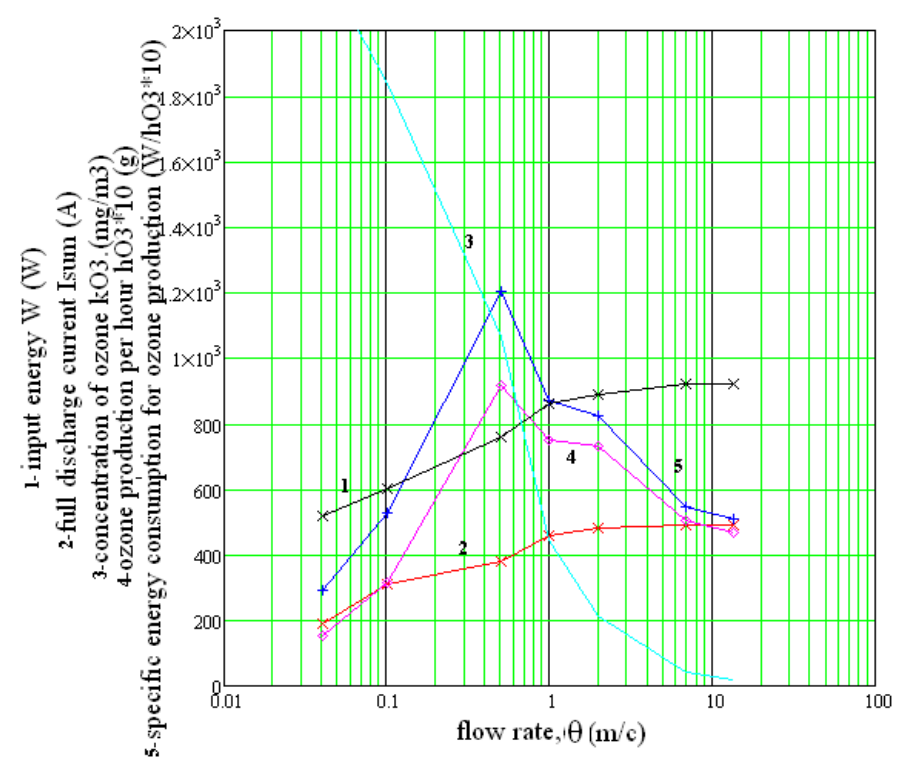

Figure 5. The dependence of the power input into the gas $W(1), I_{\text {sum }}(2)$ the concentration of ozone $\mathrm{kO}_{3}(3)$, hour of ozone production $\left(\mathrm{GO}_{3}\right)(4)$ and specific energy consumption for ozone production $\left(\mathrm{W} / \mathrm{GO}_{3}\right)(5)$ from the air flow rate $(\theta)$.
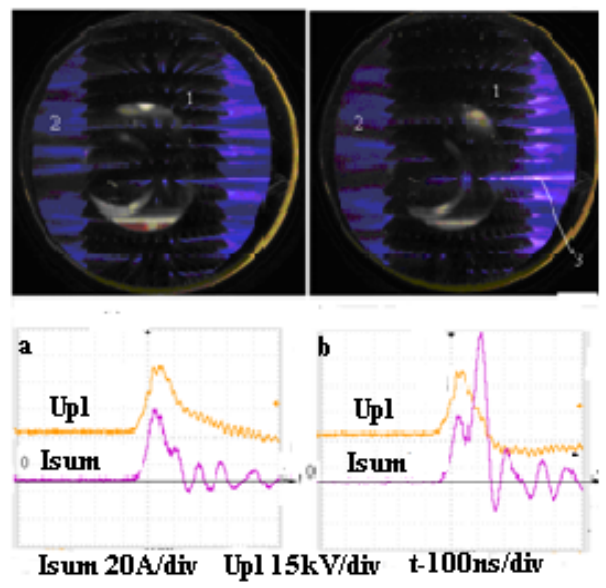

Figure 6. The dependence the $I_{\text {sum }}$ and optical spectrum from air flow rate $(\Theta)$ (a) $\Theta=0.01 \mathrm{~m} / \mathrm{s}$ (b) $\Theta=1 / 5 \mathrm{~m} / \mathrm{s}$ RC l = $100 \mathrm{~cm}, \mathrm{D}=12 \mathrm{~cm} ; 1-$ MPD electrode, 2-primary streamer 3 - second streamer.

The above results showed that the highest efficiency of the plant is provided with the values of the order of $\mathrm{E} 6.5$ $\mathrm{kV} / \mathrm{cm}$ and duration of pulse $\sim 0.5 \mu \mathrm{s}$ in Figure 7. In this case on the one hand streamers cover the all inter electrode gap and thereby maximize the conversion zone but the other hand do not allow the streamer breakdown occur, whereby instead impurities conversion of nitrogen oxides is generated. Another factor that significantly affects the conversion efficiency is the design of the RC, which is excited by streamer corona. Our previous experiments showed [5] that the energy efficiency of introduction of $\mathrm{W}$ increases with increasing distance between and using MP (Figure 6). So increasing the diameter of the RC from 30 to $260 \mathrm{~mm}$ with the replacement of the electrode increases the current 30 to $200 \mathrm{~A}$ at the same pulse voltage in $\mathrm{RC} E=6.5 \mathrm{kV} / \mathrm{cm}$. This is due not only to an increase in the discharge point that the wire is not more than $2001 / \mathrm{m}$, and that the Isum at $\mathrm{E}=$ const. is proportional to Upl [6]. In terms of increasing the efficiency of clearing it is desirable to have as much as possible the diameter of RC. But D of our RC be limited to $260 \mathrm{~mm}$ due to the complexity of designing high-frequency generators for voltage more than $100 \mathrm{kV}$. 
Because of the short duration of the pulse, the value introduced into the discharge gap volume energy less than $20 \mathrm{~J} / \mathrm{m}^{3}$. Given that the conversion to a concentration of impurities of $100 \mathrm{ppm}$ requires the energy density of at least $10^{4} \mathrm{~J} / \mathrm{m}^{3}$, it is obvious that the pulse repetition frequency (f), industrial installations should be much higher than $100 \mathrm{~Hz}$.

\section{Installations for Waste Gas Cleaning by Means of LTP}

All of the above have been taken into account in the establishment in FMKB "Horizon" series of installations for cleaning waste gas of contaminants via LTP. Under the scheme of Figure 1 developed and commercially available modular treatment plants ranging from 1 to $8 \mathrm{~kW}$ performance $(0.3-15) \times 10^{3} \mathrm{~m}^{3} / \mathrm{h}$, whose photos are shown in Figures 8-12. Main specification of units are presented in Table 1; results of cleaning efficiency in Table 2.

Figure 13 show cleaning exhaust of the diesel engines KIA "Sportage" SL SLS power $136 \mathrm{~kW}$, volume $2 \mathrm{l}$ (1000 rpm) using mobil unit ( $\mathrm{RC} \mathrm{l}=1 \mathrm{~m}, \mathrm{D}=0.2 \mathrm{~m}$.) Upi $=55 \mathrm{kV}, \mathrm{f}=900 \mathrm{~Hz} . \mathrm{W}=2 \mathrm{~kW}$ (Figure 10). They show that it is possible to completely remove $\mathrm{NO}$ partially $\mathrm{NO}_{2}$ and a significant amount of soot (Figure 13).

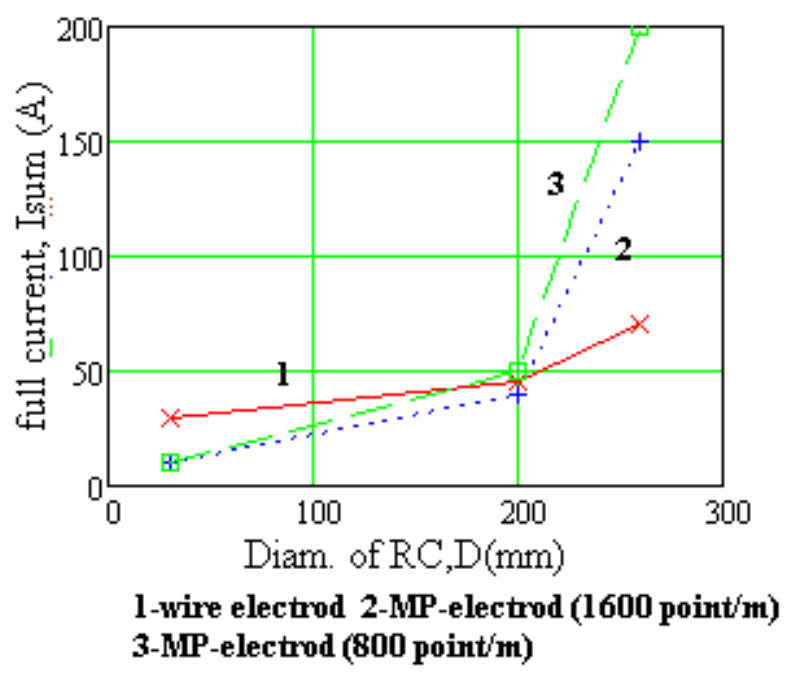

Figure 7. The dependence the $\mathrm{I}_{\text {sum }}$ from $\mathrm{D}$ of $\mathrm{RC}(\mathrm{l}=1 \mathrm{~m})$ for various types of electrodes $\mathrm{E}=6.5 \mathrm{kV} / \mathrm{cm}$.

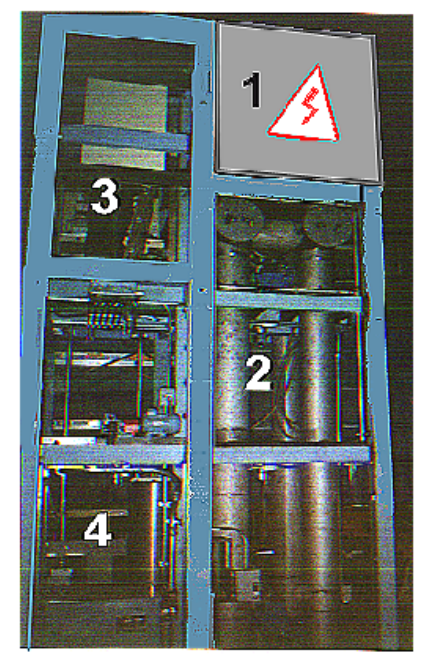

Figure 8. Pilot plant for the purification of NOx Torch furnaces Butte Montana US []. 1-PGF, 2 = RC, 3-Control room, 4-HV charge. 


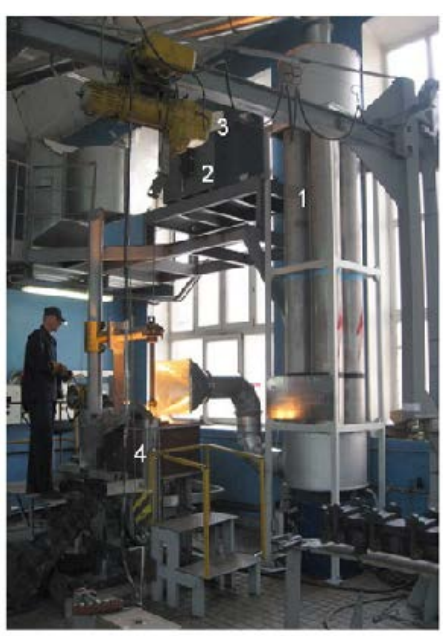

Figure 9. Industrial plants for the abatement of remelting SPC Gas Turbine "Salute" 1-RC, 2-PGF, 3-HV charge, 4-Furnaces.

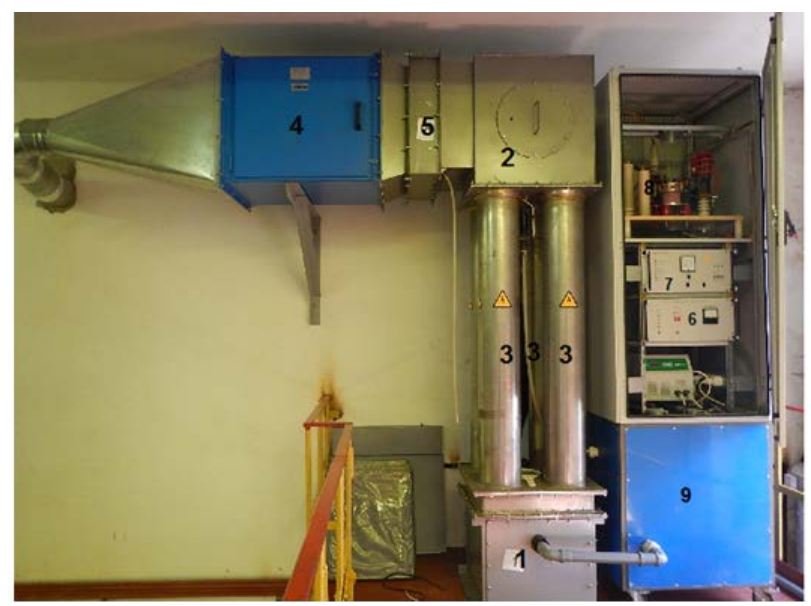

Figure 10. Industrial plants for the purification of sewage pump stations 1,2,3,4-block of RC, 5-ozone destructor, 6-control block, 7-HV charge, 8-PGF.

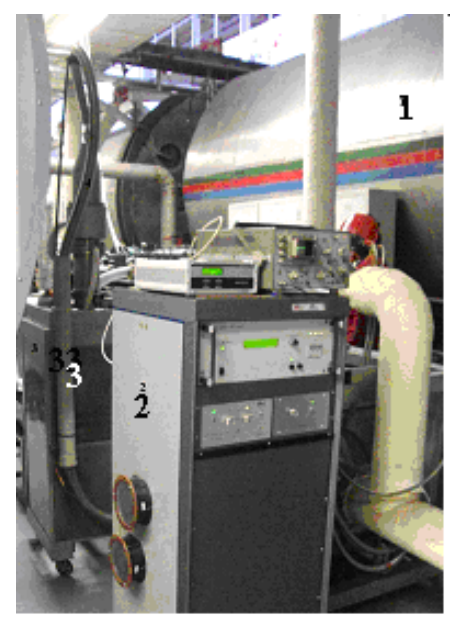

Figure 11. Mobil unit in project "Mars 500”. 1-“Mars landing module”; 2-PGF with control board; 3-Reactor chamber. 

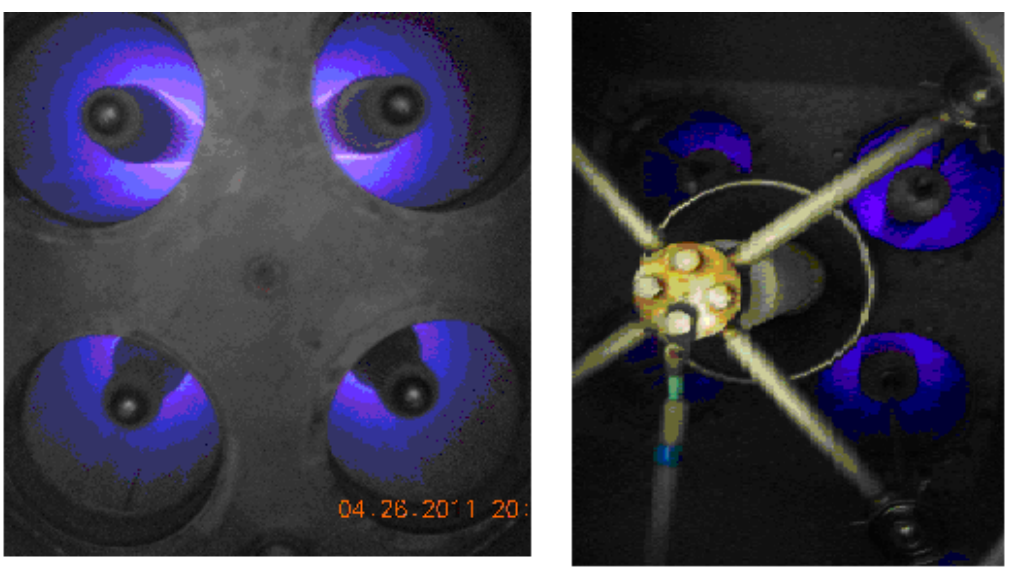

Figure 12. Present photo of LTP created by nanosecond corona discharges above and below RC.
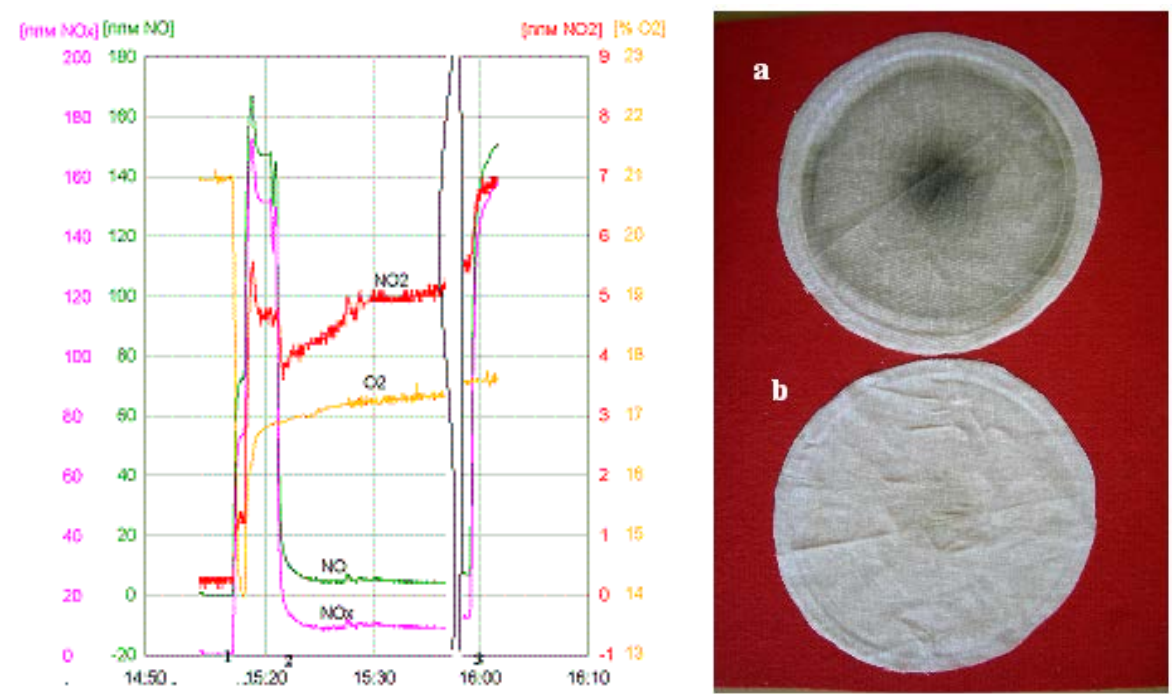

Figure 13. Cleaning exhaust of the diesel engines KIA "Sportage” SL SLS power $136 \mathrm{~kW}, 1-$ switch engine, 2-3-clean unit in progress. One hour test by measuring the amount of soot in the exhaust of the diesel engine (a) without purification (b) clean unit in progress.

Table 1. Specification.

\begin{tabular}{|c|c|c|c|c|c|}
\hline \multirow[b]{2}{*}{ Name of the parameter } & \multirow[b]{2}{*}{ Dimension } & \multicolumn{4}{|c|}{ Value/characteristic } \\
\hline & & $\begin{array}{l}\text { SPC Gas Turbine } \\
\text { "Salute" Moscow }\end{array}$ & $\begin{array}{c}\text { Project "Mars 500" } \\
\text { Moscow }\end{array}$ & MSE, Butte, USA & $\begin{array}{l}\text { Pump station } \\
\text { Moscow }\end{array}$ \\
\hline Gas flow rate max & $\mathrm{m}^{3} /$ hour & 5000 & 200 & 1000 & 15,000 \\
\hline Power max & $\mathrm{kW}$ & 6 & 2 & 4 & 6 \\
\hline Pulse voltage max & $\mathrm{kV}$ & 115 & 90 & 150 & 90 \\
\hline Pulse duration & ns & 450 & 120 & 250 & 250 \\
\hline Pulse frequency max & $\mathrm{Hz}$ & $100-400$ & $100-1000$ & 120 & 1000 \\
\hline Reactor chamber & & 4-tube wet-type & 1 tube & 4-tube & 4 - 6 tube \\
\hline Denison & $\mathrm{m}$ & $1 \times 2.5 \times 5$ & $0.6 \times 1.5 \times 2$ & $4 \times 4 \times 6$ & $2 \times 1.5 \times 4$ \\
\hline Weight & ton & 1.5 & 0.2 & 2 & 0.6 \\
\hline
\end{tabular}


Table 2. Cleaning efficiency.

\begin{tabular}{|c|c|c|c|c|c|}
\hline Type of pollution & Concentration $\mathrm{mg} / \mathrm{m}^{3}$ & $\begin{array}{l}\text { Gas flow } \\
\text { rate, } \mathrm{m}^{3} / \mathrm{h}\end{array}$ & $\begin{array}{c}\text { Purification } \\
\text { degree, \% }\end{array}$ & $\begin{array}{c}\text { Specific } \\
\text { power, } \\
\text { W-h/m } / \mathrm{m}^{3} \mathrm{mg}\end{array}$ & Installation site \\
\hline $\mathrm{SO}_{2}$ & 5000 & 800 & 70 & 0.002 & Non-Ferrous Metals Plant, \\
\hline $\mathrm{NO}_{\mathrm{x}}{ }^{*}$ & 3000 & 36 & 95 & 0.006 & MSE Corp., USA \\
\hline Toluene + Benzene & 300 & 50 & 90 & 0.13 & with addition of ammonia \\
\hline Aerosol $\mathrm{CrO}_{3}$ & 10 & 200 & 99 & 0.2 & “FSUE” SIC “Salut” \\
\hline NOx, soot & 600,15000 & 50 & 90 & $0.016,10^{-4}$ & GP5-DE 5 kW \\
\hline HF, aerosol & 30 & 5000 & 95 & 0.06 & “FSUE” SIC “Salut” \\
\hline $\mathrm{H} 2 \mathrm{~S}$ & 150 & 1000 & 0.2 & 0.02 & Sewage treatment tank \\
\hline \multicolumn{6}{|c|}{ Moscow pump station } \\
\hline Canalization odour & & 5000 & No odour & $0.8^{* *}$ & \\
\hline $\mathrm{H}_{2} \mathrm{~S}$ & 16,2 & 5000 & 80,4 & $0.8^{* *}$ & ${ }^{* *}$ Specific power $\mathrm{W}-\mathrm{h} / \mathrm{m}^{3}$ \\
\hline Ammonia & 0,55 & 5000 & 89,8 & $0.8^{* *}$ & \\
\hline
\end{tabular}

\section{Conclusions}

1) The results of experimental studies of plasma parameters generated by nanosecond corona discharge applied to plants for plasma cleaning emissions.

2) For the first time experimentally shown that it is possible streamer breakdown of air gaps of a few centimeters.

3) The factors affecting the efficiency of the treatment plants were determined.

4) The descriptions photos and specification pilot and industrial plants.

5) Presented main results of cleaning emissions from industrial and communal enterprises, diesels engine.

\section{References}

[1] Masuda, S. and Nakao, H. (1986) Removel of $\mathrm{NO}_{\mathrm{x}}$ in the Exhaust Gas from a Diesel Engine Using Pulsed Plasma. IEEE-IAS Annual Conference, Denver, 1173-1182.

[2] Ponizovsky, A.Z. and Shvedchicov, A.P. (1994) The Removal of Ecologically Harmful Admixtures from Air by Use of Pulse Corona Discharges Technique and UV-Radiation. Pros. Third Inter. Conf. on Photochemical Conventions and Storage of Solar Energy (IPS-10), 24-29 July 1994, H116.

[3] Ponizovskii, A.Z. (2007) Cleaning the Ventilation Emissions by Pulsed and DC Corona Discharges. "Nauchtekhlitizdat" Ecological Systems and Devices, №11, 9-14. (In Russian)

[4] Mel’nikov, V., Ponizovsky, A., Gosteev, S., Maevsky, V. and Ponizovsky, L. (2009) Probe Measurements of Parameters of Cathode-Directed Single Streamers in a Multipoint Corona Discharge System. Proceedings of the 19th International Symposium on Plasma Chemistry, Bochum, 26-31 July 2009, 1.5.04.

[5] Shockley, W. (1938) Currents to Conductors Induced by a Moving Point Charge. Journal of Applied Physics, 9.

[6] Ponizovskiy, A., Abramov, A., Gonchrov, V., Gosteev, S., Ponizovskiy, L., Potapov, V.A. and Shvedchicov, A.P. (1993) Optimization of Parameters of Electro Physical Equipment for Air Purification. Russian Electrical Engineering, 64, 77-83. 